\title{
Characteristics of Confined Blast Loading in Unvented Structures
}

\author{
Yi Hu, Chengqing Wu*, Matthew Lukaszewicz, Jonathan Dragos, \\ Jiajing Ren, Matthew Haskett \\ School of Civil, Environmental and Mining Engineering, \\ the University of Adelaide, SA, Australia
}

\author{
Received on 18 Sept 2010, Accepted on 22 Dec 2010
}

\begin{abstract}
Confined blast loading occurs in many scenarios and the effects of confined blast loading may result in more serious damage to buildings due to multiple shock reflections (Shi et al. 2009). However, spherical charges are assumed for all confined explosive-effects computations in modern standards for blast-resistant design such as UFC-3-340-02 (2008) and the soon-to-be published ASCE Standard for the Blast Protection of Buildings (ASCE forthcoming) without consideration of effects of charge shape on the distribution of reflected overpressure and impulse. As confinement is an aggravation factor of explosion effects, analysis and design of infrastructure under critical scenarios of confined blast loading should take the aggravation factor into consideration. This paper is to develop a numerical model for prediction of blast loads inside unvented structures as a result of variation of the charge shape, charge orientation, geometries and volumes of confined chambers. A finite element program, AUTODYN (Century Dynamics, 2003), is utilized extensively to generate a model which is capable of being calibrated with the experimental results conducted by Wu et al. (2010) in external conditions and by Zyskowski et al. (2004) in a confined small box. The calibrated AUTODYN model is then used to conduct parametric studies to analyze the effects of the variation of charge shape, charge orientation, chamber geometry and chamber volume on the peak reflected overpressure and impulse on the walls of the chamber. The quasi-static overpressure for fully confined blast loading is characterized and the simulated results are used to derive the relationships between the quasi-static overpressure and scaled distance for the fully confined blast loading. Discussion is made on characteristics of fully confined blast loading inside chambers.
\end{abstract}

\section{INTRODUCTION}

Due to rising accidental explosions and terrorist bombing attacks in confined scenarios such as tunnels in urban cities and suburban areas, evaluation of confined explosion hazards and their consequence on infrastructure at high risks is important to the safety of people and installations. As confinement is an aggravation factor of explosion effects, analysis and

*Corresponding author. E-mail addres: cwu@civeng.adelaide.edu.au 
design tools are required to simulate critical scenarios to help protect civil infrastructure. However, the problem of a confined explosion is more complex than in the free field and therefore is less addressed at current guidelines such as UFC-3-340-02 (2008) and ASCE (ASCE forthcoming). The basis of confined blast loading analysis is accounting for the shock wave interactions with the confinement. For a fully confined explosion, current approaches to predict blast loads are limited. Thus further study of confined, explosion induced blast wave propagation and interaction with structures is necessary to improve current guidelines.

Considerable research work including numerical and experimental investigations has been conducted on prediction of blast loads on buildings from external explosions (Wu et al. 2010, Zhou and Hao 2007). The most simple and most studied scenario that deals with wave interaction is an external explosion in the proximity of an obstacle (Zhou \& Hao, 2007). The partially confined blast loading has received attention in recent years because civil engineers needed guidance on how to design structural systems to withstand various acts of terrorism. Such problems can occur from an explosion in an urban area in proximity to tall buildings in complex city geometries (Remennikov \& Rose 2005, Smith \& Rose 2006). However limited information is available on the characteristics of confined blasts, and the current extent and methods for characterizing the corresponding loading on structures.

The UFC-3-340-02 guideline states that in a confined scenario the peak reflected overpressures from an explosion in a structure will be amplified. This statement has also been proved by a study of urban blasts that the confinement provided by the street buildings can increase the peak reflected overpressure by a factor up to four (Remennikov \& Rose, 2005). Another study done by Liu et al. (2008) and Shi et al. (2009) on blast wave propagation inside a tunnel or chamber has also showed that not only the peak overpressure generated in a confined structure is higher than that of free air explosion, but also the duration of the blast wave is longer. This also enhances the impulse, which is the area under the overpressure history and is representative of the total energy imposed on the structure, thus the opportunity of survivability of the structure, or its elements are reduced. Previous studies have also demonstrated that the overpressure history is influenced by reflections and reinforcement of blast overpressures inside a structure, making it more complex than in the free field. Chan and Klein (1994) investigated the blast effects inside an enclosure for a $1.1 \mathrm{~b}$ charge placed at the centre of a rectangular bunker. The overpressure history for the left sensor is shown in Figure 1, indicating that multiple shock reflections can continue at significant magnitudes for a long period of time. The geometry of the enclosure can cause multiple reflected shocks to meet with intensities comparable to the initial free shock.

The parameters that affect the peak reflected overpressure and impulse in confined blasts are important for characterizing confined blast loading. From studies on modeling blast loads by Remennikov and Rose (2005) in complex city geometries and Liu et al. (2008) inside a

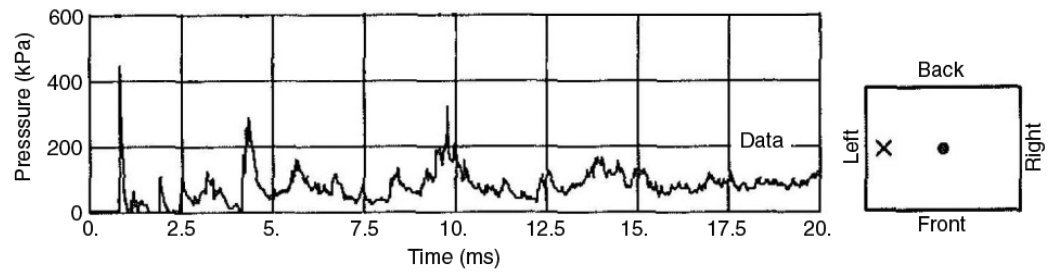

Figure 1. Overpressure history for a rectangular bunker for the left sensor (Chan and Klein 1994) 


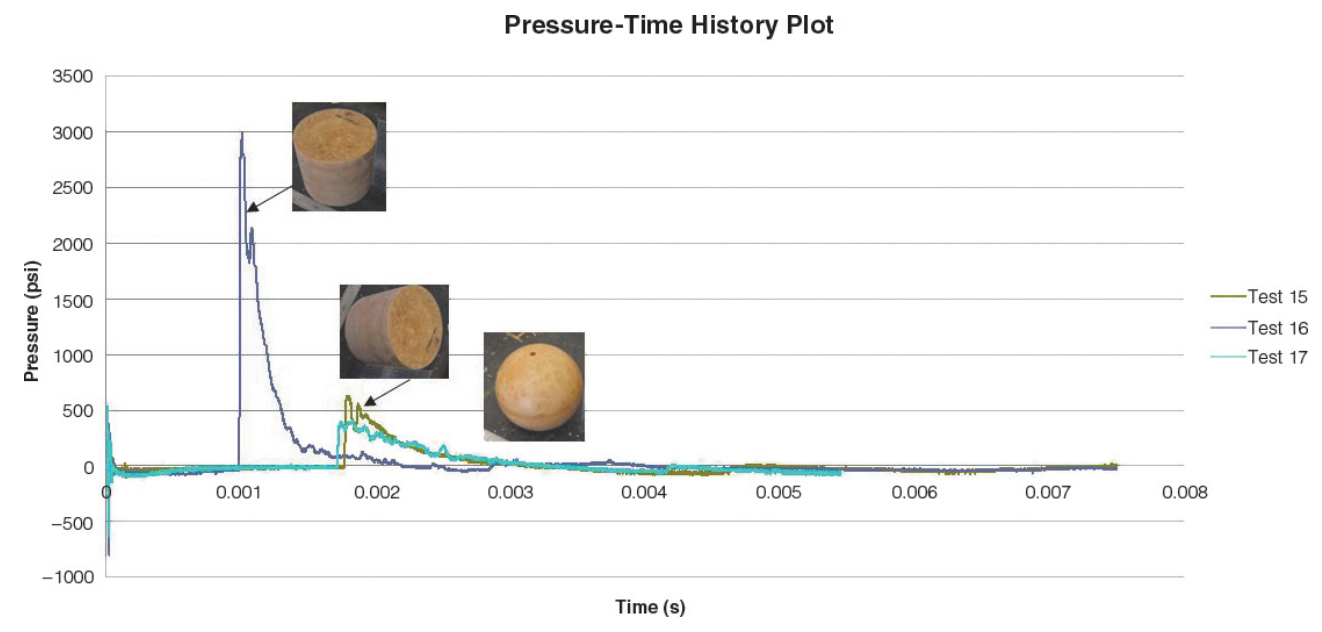

Figure 2. Experimental overpressure histories for different charge shapes and orientations from testing done by the DSTO in 2008 (Wu et al. 2010).

tunnel, it is also believed that the geometry of the confining structure and the weight of the charge and standoff distances will affect the peak reflected overpressure, its duration, and impulse greatly. However one important parameter that most of open literature fails to account for is the charge shape and orientation in confined explosions. Both experimental and numerical results in the free field have demonstrated that the orientation of cylindrical charges has a great influence on the peak reflected overpressure of the slab faces (Wu et al. 2010). A comparison of the experimental overpressure history from testing conducted by the DSTO in 2008 for cylindrical and spherical charges (L/D = 1 for all cases), for a charge weight of $0.95 \mathrm{~kg}$ and a standoff distance of $2 \mathrm{~m}$ with a $0^{\circ}$ angle of incidence (Wu et al. 2010) is shown in Figure 2. As evident from Figure 2, the peak reflected overpressure for the vertically oriented cylindrical charge in the axial direction is significantly greater than that for the horizontal oriented cylindrical charge in the radial direction and the spherical charge. It has demonstrated that for cylindrical charge with large values of length/diameter, more energy is directed in the radial direction, and for small values of $L / D$, more energy is directed in the axial direction (Wu et al. 2010). The overpressure history will be more complex for a confined explosion under such circumstances (Baker et al. 1983). In a fully confined chamber environment, the overpressure history will maintain to a constant permanent static overpressure (also called quasi-static overpressure) after certain period caused by the explosive products since there are no openings to release overpressure as shown in Figure 3. However, it is not known how long the shock wave will last before it stabilizes to a constant permanent static overpressure. Thus further research to characterize the shock wave duration and quasi-static overpressure is necessary.

As discussed above, limited published information exists for non spherical charges in confined environments. Our previous studies (Wu et al. 2010) have clearly shown that charge shape and orientation have a substantial influence on peak reflected overpressure and reflected impulse for external blast loading. It is believed that charge shape and orientation will also have significant effects on confined blast loading although it might not be as great as that in unconfined conditions. Since most warheads are cylindrical rather than spherical (Tham 2009), characterizing blast waves from cylindrical charges in confined scenarios is of 


\section{Reflected Pressure and Time History}

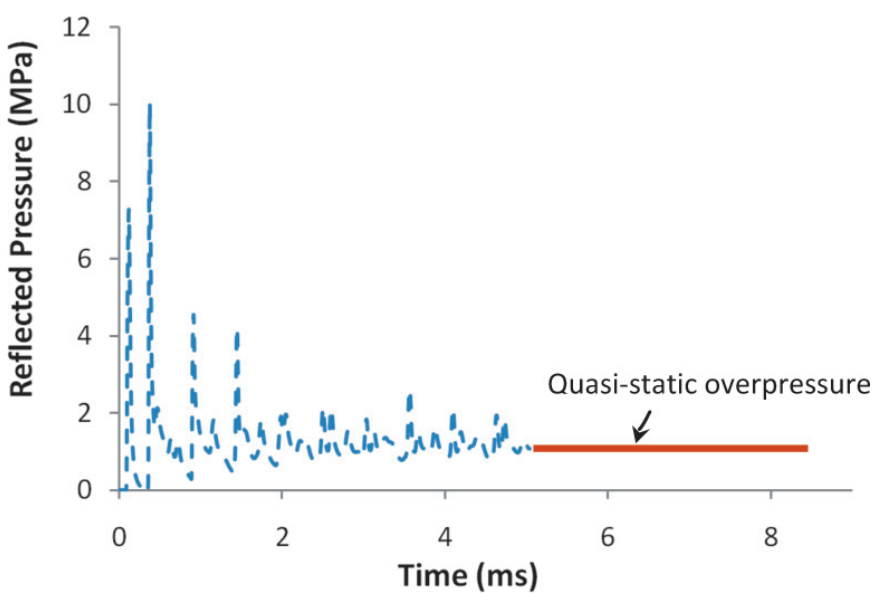

Figure 3. Typical quasi-static overpressure in a fully confined chamber

practical relevance. Due to the limitations of modern guidelines such as UFC-3-340-02, AUTODYN (Century Dynamics, 2003) is used to develop simple and reliable methods for the systematic investigation of the effects of charge shape, charge orientation, charge weight, chamber volume and chamber geometry for fully confined blast loads. To establish confidence using the AUTODYN finite element model, it was first validated using data recorded from the external testing program conducted by Wu et al. (2010) and the numerical model was further validated using experimental data in a small scale experiment conducted by Zyskowski et al. (2004). The validated model is then used to conduct parametric studies to investigate characteristics of fully confined blast loading in a cuboid and cylinder due to different charge shapes and orientations, and charge weights. The shock wave duration and quasi-static overpressure for fully confined explosion are also derived as a function of scaled distance from the simulated results. The confined blast loading in different scenarios is characterized.

\section{VALIDATION OF AUTODYN MODEL}

AUTODYN is used to simulate the blast loading in confined geometries. Partly for the purpose to validate the numerical model, a series of small scale blast tests was conducted on a $2000 \times 1000 \times 100 \mathrm{~mm}$ reinforced concrete slab as shown in Figure 4 to study the spatial and temporal distributions of reflected overpressure and impulse as a function of charge shape and orientation (Wu et al. 2010). As shown in Figure 4, the spherical explosive Composite B with weight of $2.5 \mathrm{~kg}$ for test 17 was suspended from the frame over the slab at the standoff of $2 \mathrm{~m}$. One pressure transducer (PT1), which was located at the centre of the slab as shown in Figure 4, was used to measure the reflected overpressure history. Details of the test set up could be found elsewhere (Wu et al. 2010). Figure 5 shows the configuration of the numerical model used to simulate the blast testing. In the numerical model, the reinforced concrete slab was modeled as a rigid reflecting surface and the whole domain was assumed to be symmetric and only one quarter was modelled. The remapping capability of AUTODYN is utilized in the numerical model so as to reduce the computational time during 


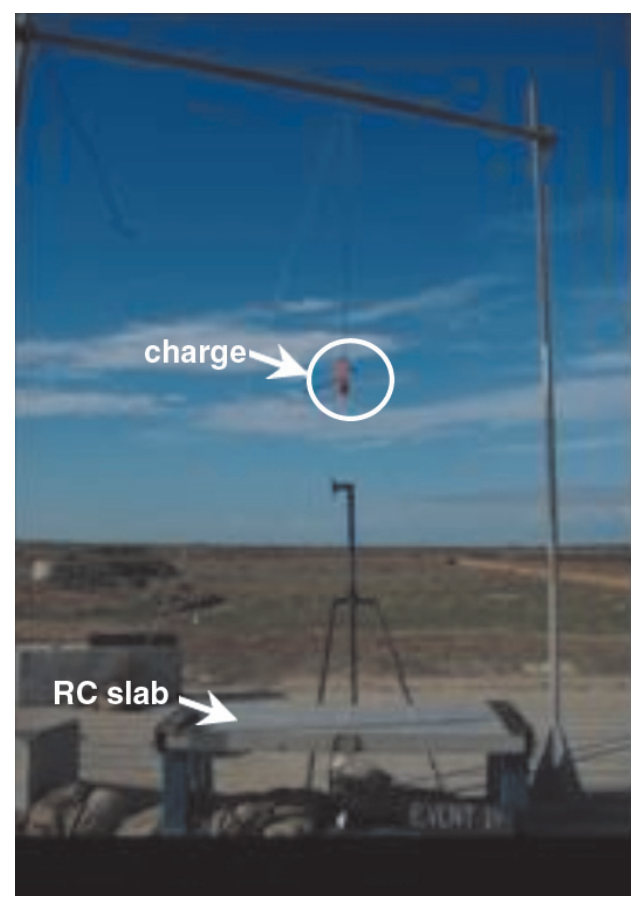

Figure 4. Test set up and layout of pressure transducers on the target slab

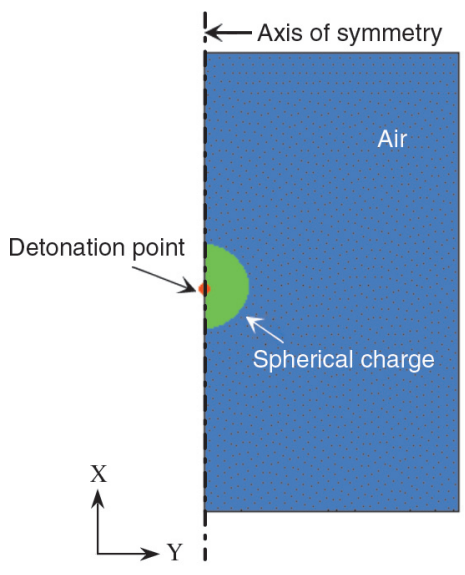

(a)

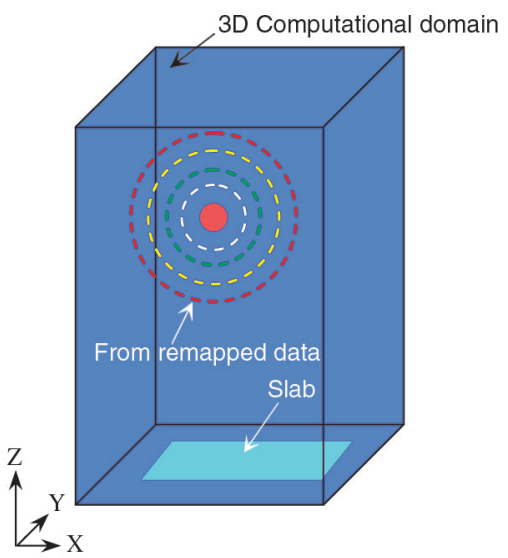

(b)

Figure 5. (a) Initial 2D set-up for simulating the detonation of spherical charges, and (b) 3D set-up for simulating blast waves interacting with structures

the initial stages of detonation and expansion of the charge. A 2D detonation calculation for the spherical charge case is remapped to a 3D computational domain. The set-up for the 2D numerical model is shown in Figure 5a. The axial-symmetry condition is imposed on the $\mathrm{x}$-axis. Figure $5 \mathrm{~b}$ shows the numerical calculation, after the remapping operation has been performed. Trial analysis was conducted to ensure that the grid sizes chosen are adequate for 
convergence and economic considerations. For this testing validation, the mesh size for the $3 \mathrm{D}$ model is selected to be $10 \mathrm{~mm}$, and the size for the 2D charge model is $1 \mathrm{~mm}$.

In the numerical model, air and TNT are simulated by Euler processor. The air is assumed to have the ideal gas equation of state:

$$
p=(\gamma-1) . \rho . e
$$

and the TNT material is modelled by the Jones-Wilkens- Lee (JWL) equation of state:

$$
p=C_{1}\left(1-\frac{\omega}{r_{1} v}\right) e^{-r_{1} v}+C_{2}\left(1-\frac{\omega}{r_{2} v}\right) e^{-r_{2} v}+\frac{\omega e}{v}
$$

where $\gamma$ is the heat specific ratio, $\rho$ is density, $e$ is internal energy, $C_{1}, C_{2}, r_{1}, r_{2}$ are constants, $\omega$ is report of the specific heat, $v$ is specific volume. In the AUTODYN model the equation of state for ideal gas can replace the JWL equation of state due to the simplification in JWL expression. The standard constants of air and TNT are retrieved from the standard AUTODYN library and the material constants are used in the numerical model, including air mass density $\rho=1.225 \mathrm{~kg} / \mathrm{m}^{3}$; air initial internal energy $e_{n}=2.068 \times 10^{5} \mathrm{~kJ} / \mathrm{kg}$; ideal air gas constant $\gamma=1.4$; and $C_{1}, r_{1}, C_{2}, r_{2}$ and $\omega$ are $3.7377 \times 10^{5} \mathrm{MPa}, 4.15,3.74713 \times 10^{5} \mathrm{MPa}$, 0.9 , and 0.35 , respectively (Century Dynamics 2003).

Figure 6 presents predicted and measured peak reflected overpressure histories for the test 17 at the location of gauge PT1. The peak reflected overpressure and the corresponding reflected impulse were overestimated by about $19 \%$ and $10 \%$, respectively. The numerical model predicted the measured values of peak reflected overpressure, positive phase duration and shape of the waveform sufficiently well to be considered to have been validated.

To further validate the numerical model, the above AUTODYN model is also used to simulate blast loading in a small scale experiment conducted by Zyskowski et al. (2004). The test setup with the small box having dimensions of $500 \mathrm{~mm} \times 400 \mathrm{~mm} \times 300 \mathrm{~mm}$ is shown in Figure 7. In the small scale experiment the hemispheric gas mixture with a TNT equivalency weight of approximately $0.315 \mathrm{~g}$ was placed on the floor. Gauges located at different points were placed to measure the incident overpressures and reflected overpressures. The whole box

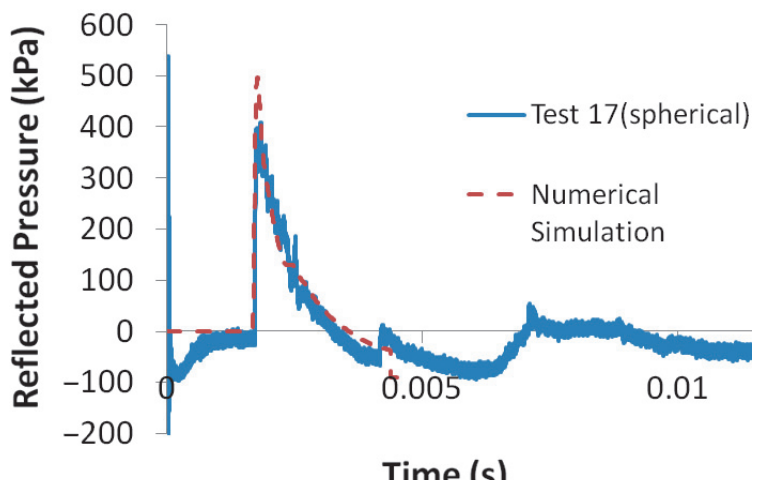

Time (s)

Figure 6. Predicted and experimentally measured reflected overpressure histories for test 17 at the location of gauge PT1 


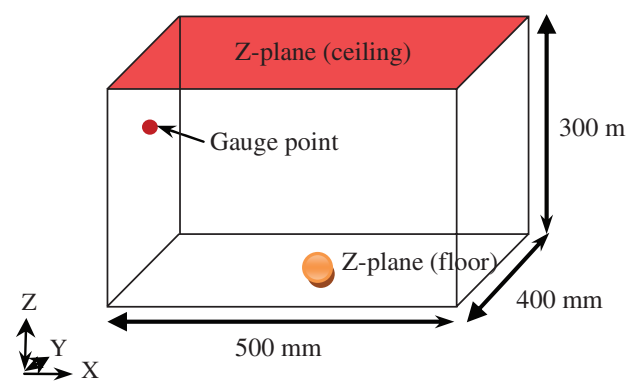

Figure 7. Small scale test set-up

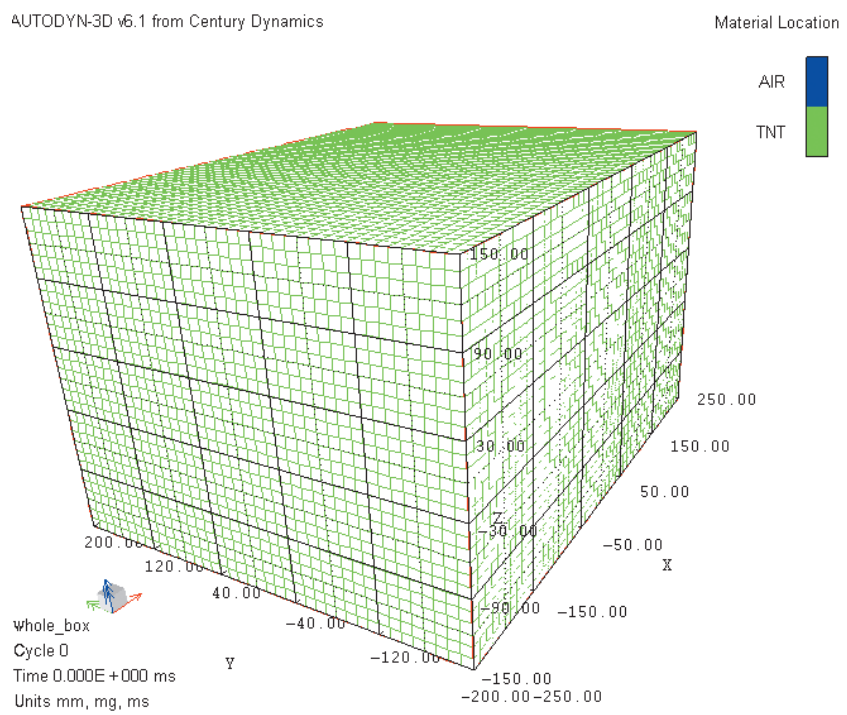

Figure 8. Numerical model of the small box

is created in a three-dimensional model as shown in Figure 8 with the mesh cell size of $10 \mathrm{~mm}$ in the study. The charge is detonated at the floor centre of the box, and the blast wave propagates radially outwards from the detonation point. Figure 9 shows a comparison of experimental data with the corresponding simulated overpressure history about the gauge point at the location of $(190,200,255)$ as shown in Figure 7 . As expected, the simulated results in terms of amplitude, arrival time and wave profile agree well with the experimental data, indicating that this AUTODYN model can also be used to predict confined blast loading accurately.

\section{CHARACTERISTICS OF CONFINED BLAST LOADING IN THE SMALL BOX}

The numerical model validated in Section 2 is utilized to conduct parametric studies for prediction of the overpressure distribution on structures as a result of confined blast loading, for a variety of blast loading scenarios. The small box as shown in Figure 6 is used to carry out the parametric studies and the explosives are put at centre of the box for all cases. With the remapping technology, the parametric studies are carried out to study the variation in 


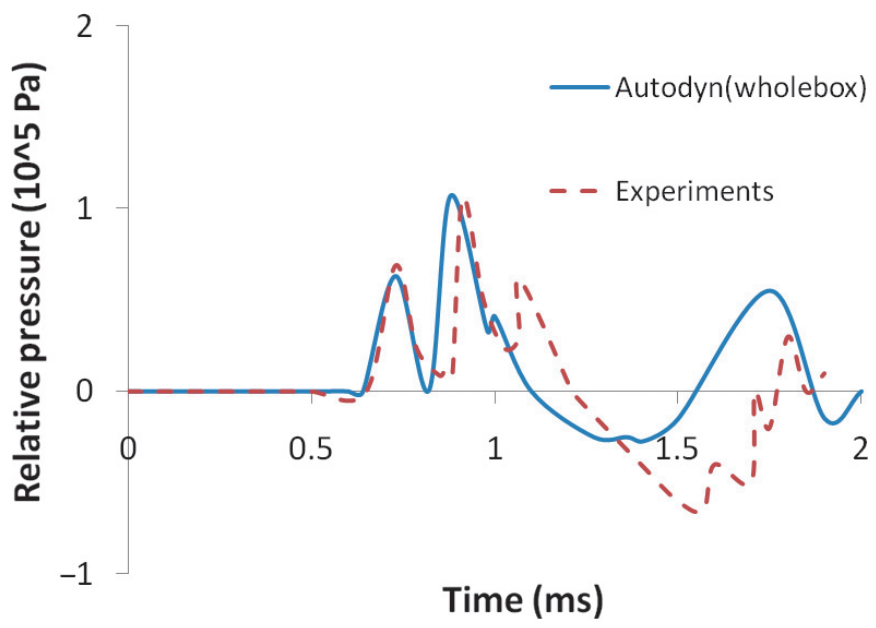

Figure 9. confined blast loadings from the experiment and the numerical models

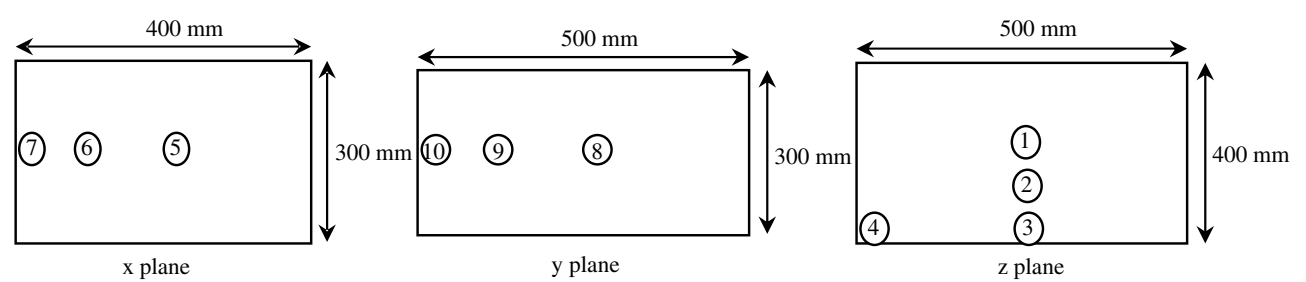

Figure 10. Gauges set on three planes of the small box

reflected overpressure with location on a small box by changing the charge orientation, the charge weight, and the charge shape. Gauges are placed on three planes as shown in Figure 10 to measure reflected overpressure histories. As observed, more gauges are put on $\mathrm{z}$ plane (the roof as shown in Figure 7) since it is regarded as the critical surface that possibly produces the largest peak overpressure from the small box.

Figure 11 compares the reflected overpressure histories at different gauges for $100 \mathrm{~g}$ TNT explosive with a spherical charge. As observed, the peak reflected overpressure varies from 10.1 MPa at gauge 8 to 57.2 MPa at gauge 4, more than five times. Multiple shock reflections in Figure 11 are observed at almost all gauges (except gauge 4) at significant magnitudes for a long period of time. However it is assumed at the current guideline UFC-3-340-02 that the reflected overpressure inside a container is uniformly distributed with one peak shock reflection only.

It should be noted that although most guidelines (UFC-3-340-02) assume a uniform overpressure distribution for confined blast loading and only a few manuscripts (Baker et al. 1983) showed qualitatively more complex distributions, such as the possibility of overpressure increase in corners (Savir et al. 2009). Figure 12 shows peak overpressure distribution along center lines of the ceiling or floor (z plane), side walls (x plane) and front or rear walls (y plane) in the fully confined small box with a spherical charge weight of $100 \mathrm{~g}$. As can be seen, the variation of peak overpressure between the center and corner along the ceiling could be more than 2 times. The peak overpressure distribution of along center 


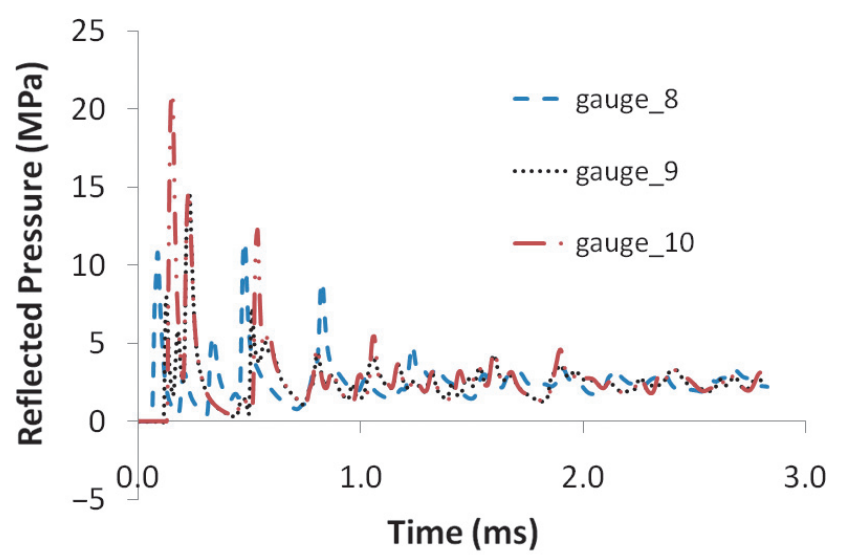

$\mathrm{x}$-plane
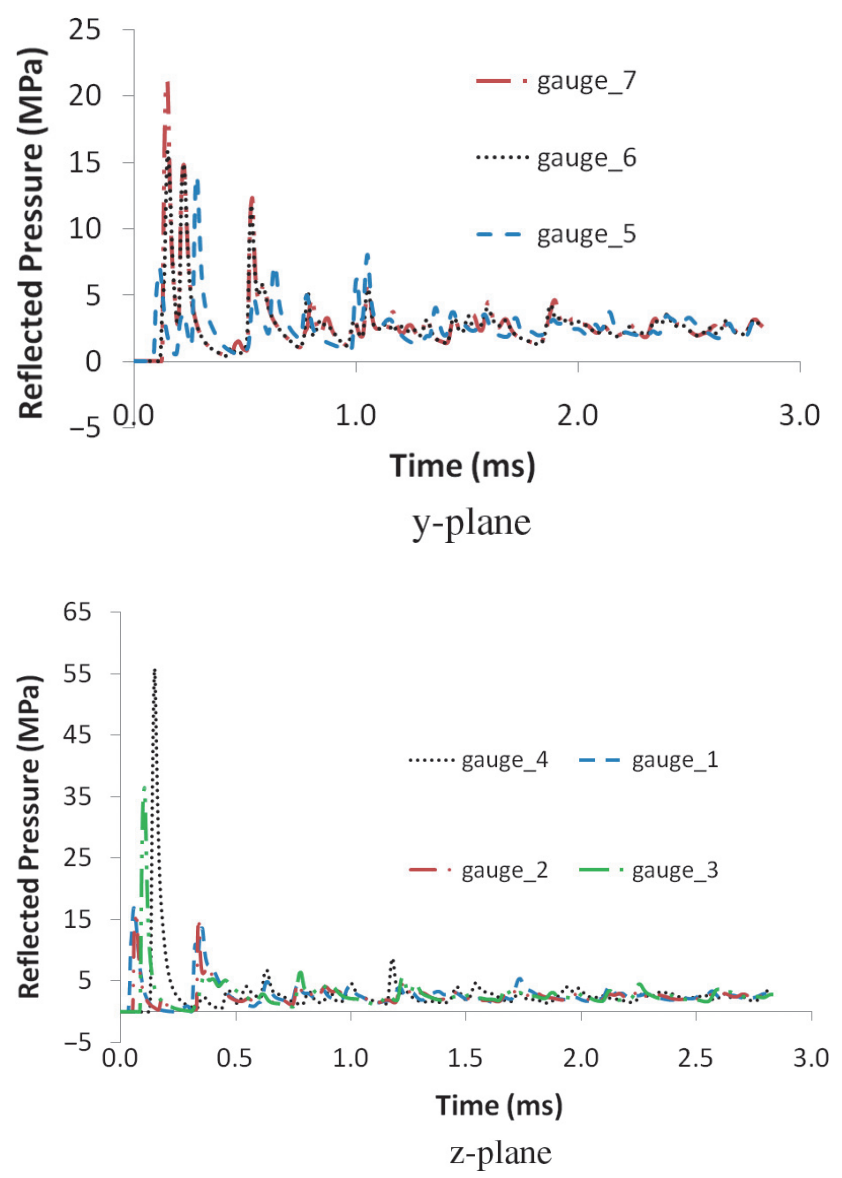

Figure 11. A comparison of reflected overpressure histories on three planes for $100 \mathrm{~g}$ explosive with spherical charge 


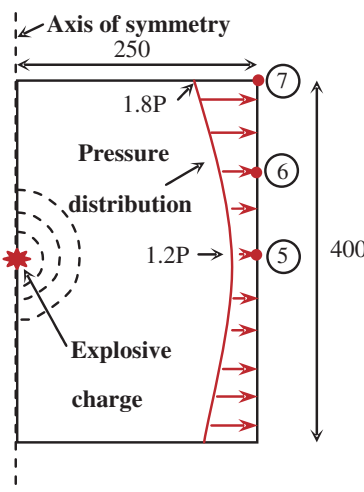

(a) $\mathrm{x}$ plane

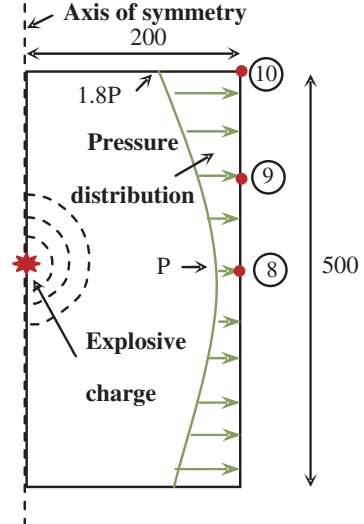

(b) y plane

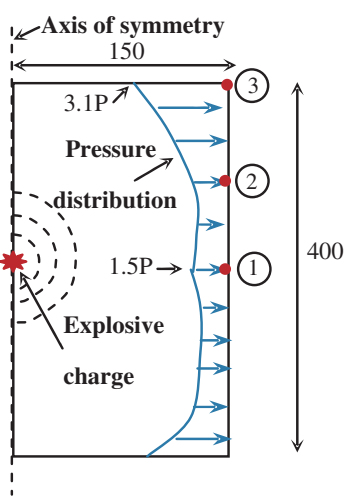

(c) z plane

Figure 12. Peak overpressure distributions along centre lines of $x$ plane, y plane and $\mathrm{z}$ plane of the small box with a $100 \mathrm{~g}$ spherical charge

lines of the ceiling or floor (z plane), side walls (x plane) and front or rear walls (y plane) in the confined small box with a $100 \mathrm{~g}$ cylindrical charge $(\mathrm{L} / \mathrm{D}=2)$ of vertical orientation along $\mathrm{z}$ axis is shown in Figure 13, quite different from the assumption of a uniform overpressure distribution by UFC-3-340-02. As observed in Figure 13 the variation of overpressure distributions is much large than that due to spherical charge, indicating that the assumption of a uniform overpressure distribution for confined blast loading by UFC-3-340-02 might produce much more inaccurate results, especially for cylindrical charges.

Prior studies have shown that the orientation of cylindrical charge has a substantial effect on the peak reflected overpressure of the slab from external airblast as shown in Figure 2 (Wu et al. 2010). Figure 14 compares the overpressure histories at gauge 1 for the $100 \mathrm{~g}$ spherical charge and $100 \mathrm{~g}$ cylindrical charges with difference orientations in three planes.

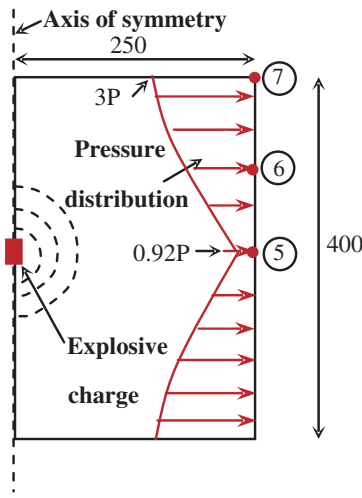

(a) x plane

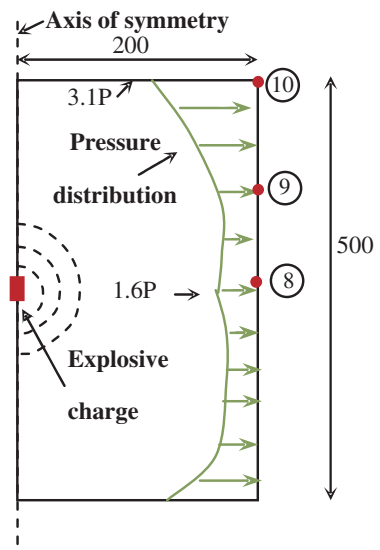

(b) y plane

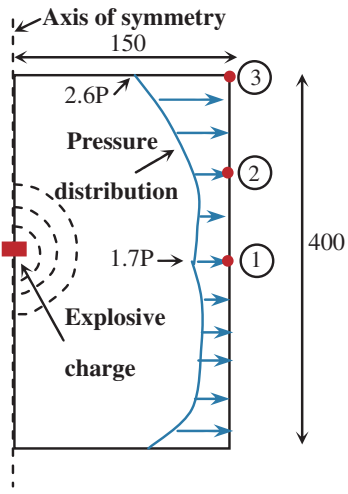

(c) z plane

Figure 13. Peak overpressure distributions along centre lines of $x$ plane, $y$ plane and $z$ plane of the small box with a $100 \mathrm{~g}$ cylindrical charge $(L / D=2) z$ axis orientation 


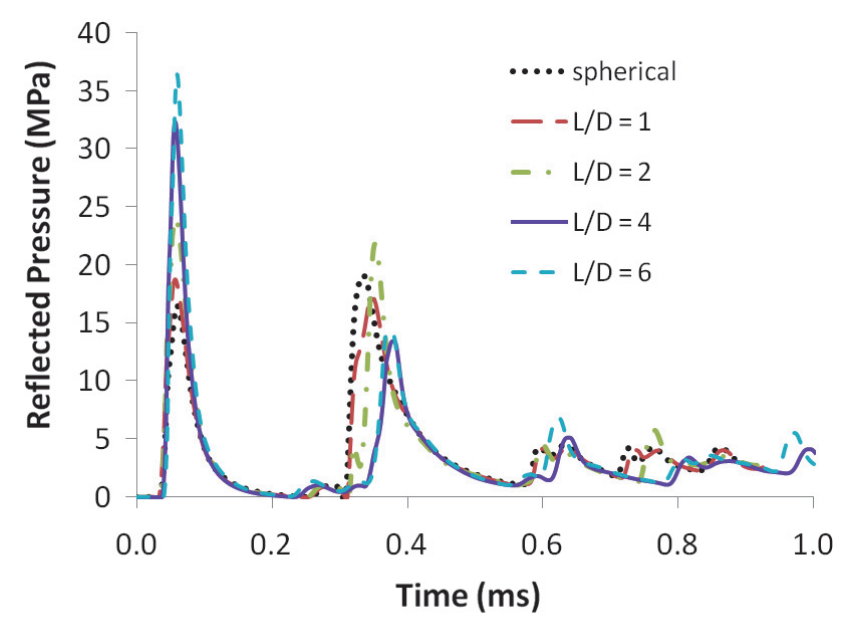

Horizontal orientation (along $x$ axis)

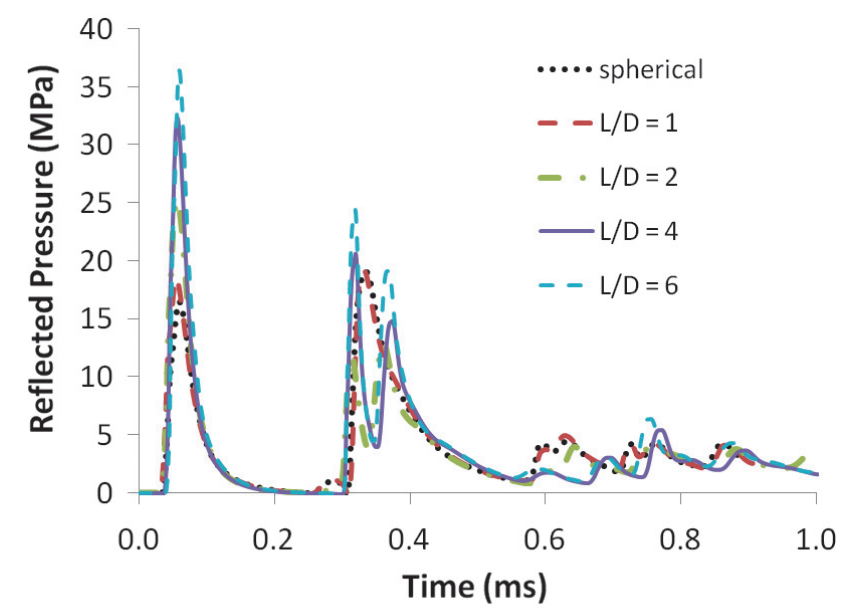

Horizontal orientation (along y axis)

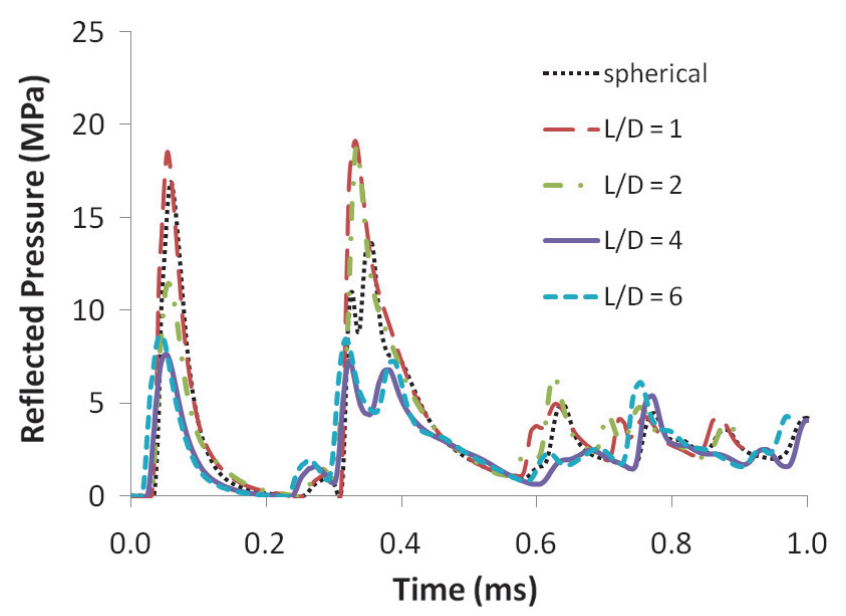

Vertical orientation (along $\mathrm{z}$ axis)

Figure 14. Reflected overpressure histories for $100 \mathrm{~g}$ cylindrical charge with three orientations at gauge 1 
It is clearly shown from Figure 14 that there is not much difference observed for overpressure histories at gauge 1 generated by the $100 \mathrm{~g}$ spherical charge and $100 \mathrm{~g}$ cylindrical charge with $\mathrm{L} / \mathrm{D}$ (length/diameter) ratio of $1: 1$ at three orientations, which is significantly different from external airblast loading where the vertically oriented cylindrical charge (along $\mathrm{z}$ axis) in the axial direction ( $\mathrm{z}$ direction) is significantly greater than that for the horizontal oriented cylindrical charge in the radial direction (along both $\mathrm{x}$ and $\mathrm{y}$ axis) and the spherical charge (Wu et al. 2010). However, there is significant difference observed for overpressure histories generated with variation of L/D (length/diameter) ratios as shown in Figure 14. As observed, the peak overpressure at gauge 1 for the $\mathrm{z}$ axis oriented cylindrical charge with L/D ratio 6 is about five times lower than that for the $\mathrm{x}$ axis oriented cylindrical charge.

\section{CHARACTERISTICS OF CONFINED BLAST LOADING}

To further study characteristics of confined blast loading, the validated numerical model is used to simulate the influence of charge shape, charge orientation, length to diameter $(L / D)$ ratios of cylindrical charges and volume and geometry of the chamber on the reflected overpressure distribution inside chambers as shown in Figure 15. Before conducting the parametric studies, the variation of peak overpressure along the ceiling (axial direction) and side wall (radial direction) for spherical and cylindrical charges inside the cube as shown in Figure 15 is investigated. Figure 16 shows the peak overpressure distributions along centre lines of three

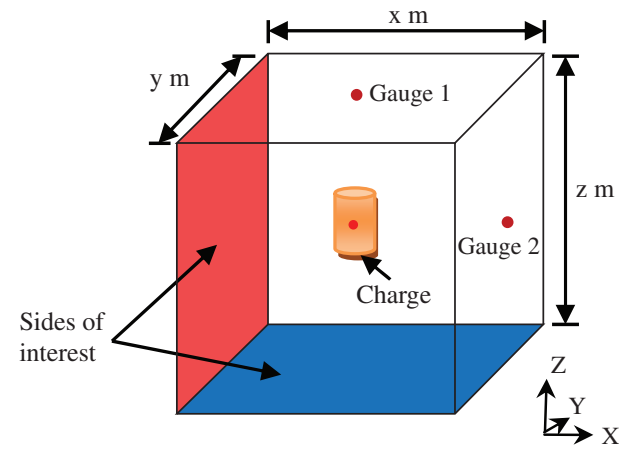

Figure 15. Chamber with explosive and detonation point in parametric studies

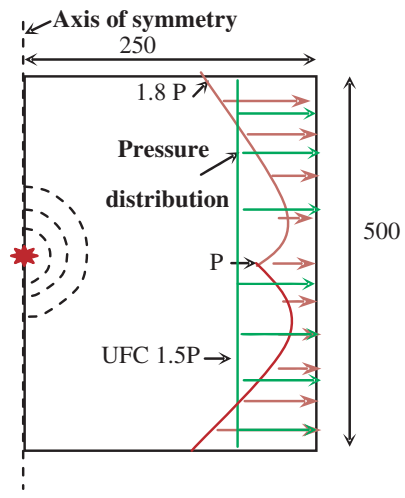

Figure 16. Peak overpressure distributions along centre lines of three planes for spherical charge $100 \mathrm{~g}$ in $0.125 \mathrm{~m}^{3}$ cube 


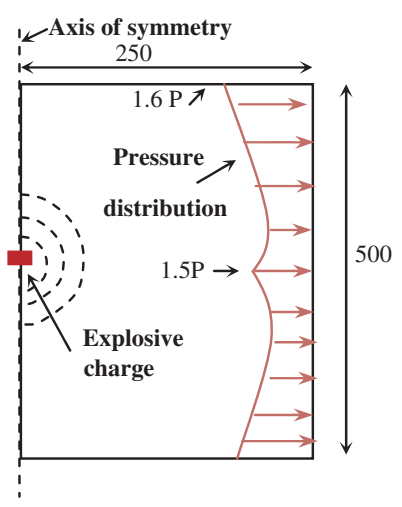

(a) Axial direction

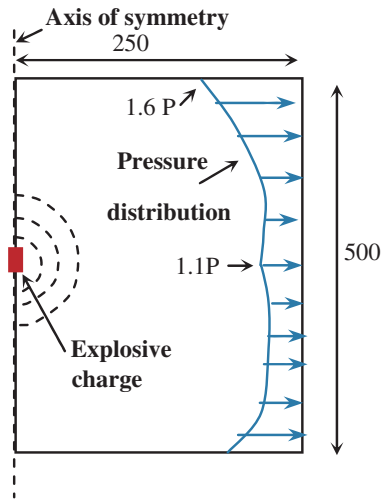

(b) Radial direction

Figure 17. Peak overpressure distributions along axial direction and radial direction for a $100 \mathrm{~g}$ cylindrical charge $(L / D=2)$ with $z$ axis orientation in $0.125 \mathrm{~m}^{3}$ cube

planes for spherical charge $100 \mathrm{~g}$ in $0.5 \mathrm{~m} \times 0.5 \mathrm{~m} \times 0.5 \mathrm{~m}\left(0.125 \mathrm{~m}^{3}\right)$ cube and the UFC prediction for the peak overpressure is also shown in the Figure 16. As observed, the variation of peak overpressure inside cubic box is much less in comparison with that inside a cuboid box as shown in Figure 12, demonstrating that the assumption of uniform overpressure distribution inside a cubic box is more accurate than inside a cuboid box. The peak overpressure distributions along axial direction and radial direction for a $100 \mathrm{~g}$ cylindrical charge $(\mathrm{L} / \mathrm{D}=2)$ with $\mathrm{z}$ axis orientation in $0.125 \mathrm{~m}^{3}$ cube is shown in Figure 17 and less variation of overpressure distribution is found again in comparison with that inside a cuboid chamber. Please note that UFC prediction for both spherical and cylindrical charges is the same in the cubic chamber.

On the other hand, blast impulse plays an important role in dynamic response analysis of structures under blast loading. For fully confined blast loading, its impulse can be characterized as shock waves and quasi-static overpressure (also called gas pressure) as shown in Figure 3. Actually for fully confined blast loading the quasi-static overpressure could dominate structural response in some cases. Thus the duration of shock waves and the quasi-static overpressure are investigated in this study.

\subsection{SHOCK WAVE DURATION AND QUASI-STATIC OVERPRESSURE}

Before shock wave duration for fully confined blast loading is determined, the quasi static overpressure should be defined. To quantify the quasi-static overpressure, the impulse for every $3 \mathrm{~ms}$ of the overpressure history is calculated. Once the difference between two continuous impulse sections is equal to or less than 5\%, the overpressure after the time $t$ is considered to be constant, that is, the quasi-static overpressure. The impulse for every $3 \mathrm{~ms}$ from time $t$ is calculated as:

$$
I_{t 1}=\int_{t}^{t+3 p a s} \operatorname{Pr}(t) d t
$$

The continuous impulse for another $3 \mathrm{~ms}$ is equal to

$$
I_{t 2}=\int_{t+3 m s}^{t+6 m s} \operatorname{Pr}(t) d t
$$


The difference between two continuous impulse sections over the impulse for the second $3 \mathrm{~ms}$ is defined as

$$
\text { tolerance }=\frac{\operatorname{abs}\left(I_{t 2}-I_{t 1}\right)}{I_{t 2}} \times 100
$$

When the tolerance defined in Eq. 5 is equal to or less than 5\%, the overpressure at time $t$ is defined as quasi-static overpressure. Figure 18 illustrates the quasi-static pressure occurs at $9 \mathrm{~ms}$ for a $100 \mathrm{~g}$ spherical charge in a $0.5 \mathrm{~m} \times 0.5 \mathrm{~m} \times 0.5 \mathrm{~m}$ cubic box, and the quasistatic pressure remains around $1.6 \mathrm{MPa}$ in the fully confined blast chamber at gauge 1 shown in Figure 15. In this case, the overpressure recorded before $9 \mathrm{~ms}$ is characterized as shock waves. Using the simulated data, a typical analysis performed for the shock wave durations and loading density for spherical charges under different volumes of the cubes at gauge 1 is illustrated in Figure 19. As shown the shock wave duration decreases with the increase of the

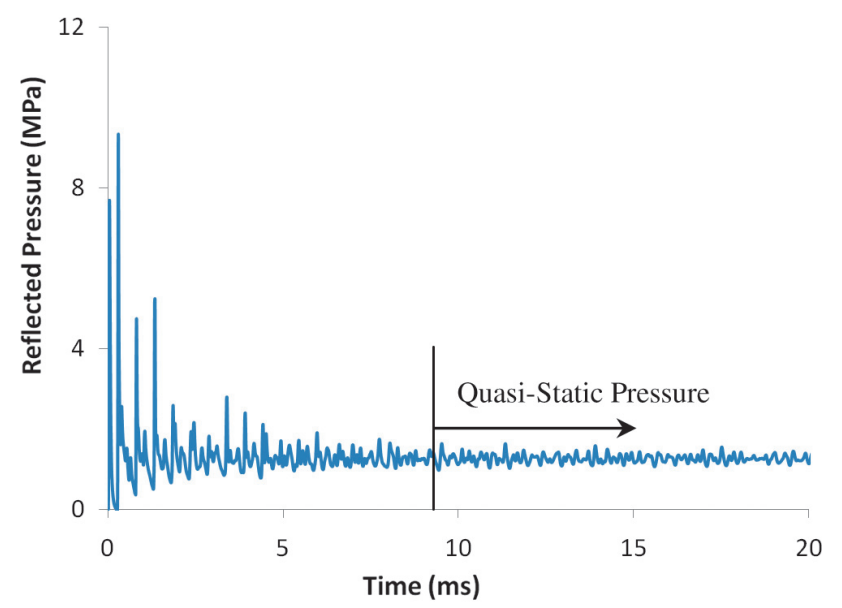

Figure 18. Overpressure history of $100 \mathrm{~g}$ spherical charge in $0.125 \mathrm{~m}^{3}$

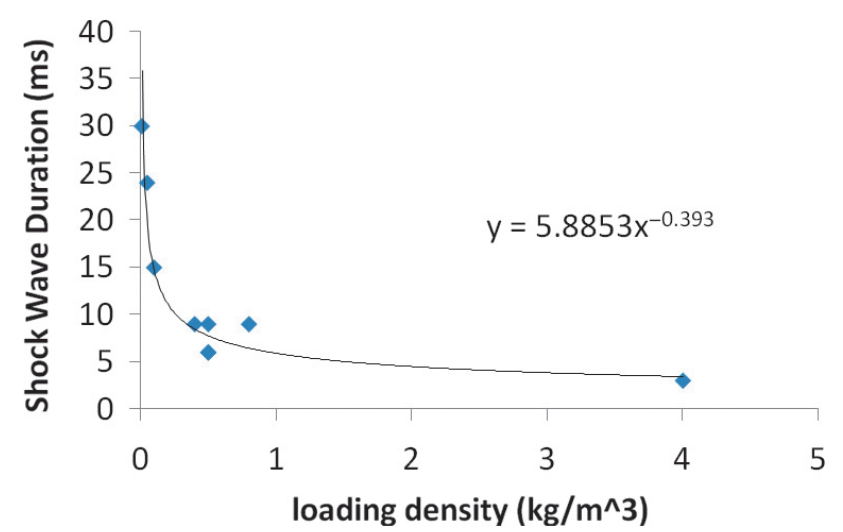

Figure 19. Shock wave duration as a function of loading density at gauge 1 


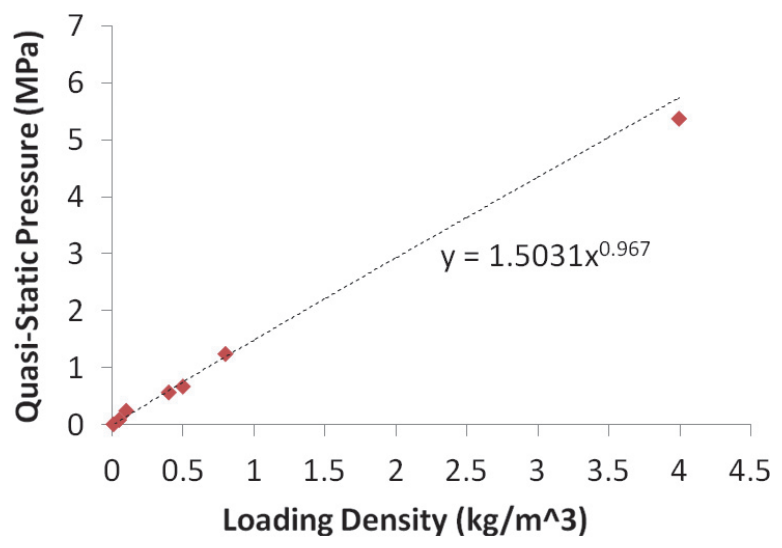

Figure 20. Quasi-static overpressure as a function of the loading density

loading density. The least-squares fitted curve for shock wave duration and the loading density is obtained as:

$$
t_{p r}=5.885 x^{-0.393}
$$

where $t_{p r}$ is the shock wave duration in $\mathrm{ms}, x$ is loading density in $\mathrm{kg} / \mathrm{m}^{3}$ (TNT weight/volume). Please note that the shock wave duration varies at different gauges.

The relationship between the quasi-static overpressure and the scaled distance for fully confined blast loading is investigated. Figure 20 provides the quasi-static overpressure v.s the loading density at gauge 1 . Based on the simulated data, the equation for the best fitted curve is derived as:

$$
P_{g(q s)}=1.50(x)^{0.967}
$$

where $P_{g(p s)}$ is the quasi-static overpressure in MPa, and $x$ is loading density in $\mathrm{kg} / \mathrm{m}^{3}$. It should be noted that although Eq. 7 is derived from spherical charges in cubic box at gauge 1 only, it is suitable for any points for spherical charges in cubic box since quasi-static overpressure is the same inside the cubic box.

\subsection{EFFECTS OF CHARGE SHAPE AND WEIGHT}

The effects of orientation of the cylindrical charge on overpressure for a cubic chamber are investigated by varying the charge weights while keeping the cubic chamber volume unchanged. The volume of the cubic chamber is $0.5 \mathrm{~m} \times 0.5 \mathrm{~m} \times 0.5 \mathrm{~m}$ with a variation of charge weights of $1 \mathrm{~g}, 10 \mathrm{~g}, 100 \mathrm{~g}, 500 \mathrm{~g}$, and $1 \mathrm{~kg}$. The cylindrical charges with length to diameter $(L / D)$ ratio of 1.0 are used in the parametric studies. Owing to symmetry, only one eighth of the model is included in the numerical analysis. Figure 21 enables a comparison of the simulated peak reflected overpressures for spherical and cylinder charges in both vertical (Z) and horizontal (X and Y) directions with the UFC-3-340-2 predictions at gauge 1. As observed there is not much difference for the simulated peak reflected overpressures between the spherical and the cylindrical charges in both vertical and horizontal directions. However, the simulated peak reflected overpressures for both the spherical and the cylindrical charges 


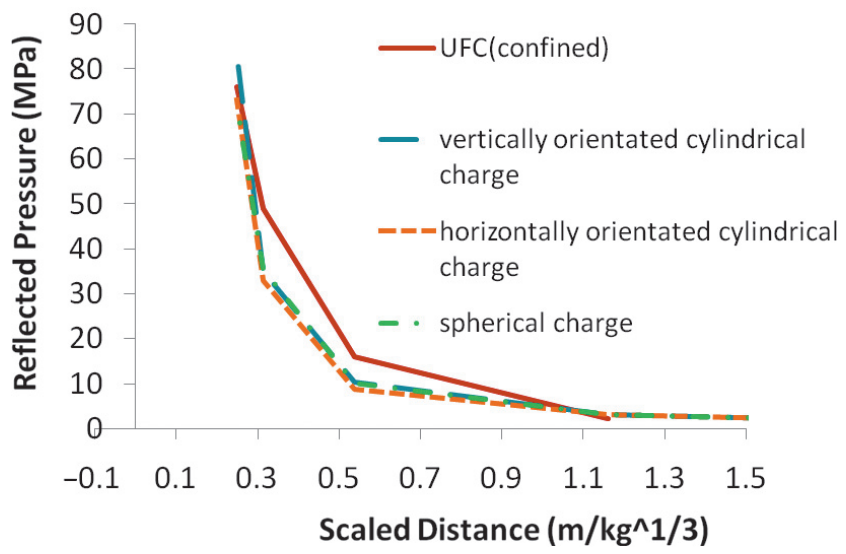

Figure 21. Peak reflected overpressure at gauge 1

in both vertical and horizontal directions at gauges 1 and 2 are substantially smaller than those predicted from the UFC-3-340-2.

\subsection{LENGTH TO DIAMETER (L/D) RATIO OF CYLINDRICAL CHARGES}

Different charge aspect ratios (length $L$ to diameter $D$ ) also influence the peak reflected overpressures in external blast loading (Wu et al. 2010). However how the charge aspect ratios affect peak overpressures in the axial and radial directions for confined blast loading was not investigated in that study. The cubic chamber volume of $0.5 \mathrm{~m} \times 0.5 \mathrm{~m} \times 0.5 \mathrm{~m}$ with charge weights of $1 \mathrm{~g}, 10 \mathrm{~g}, 100 \mathrm{~g}, 500 \mathrm{~g}$ and $1 \mathrm{~kg}$ is still used in the parametric studies. For each charge weight the variation of $L / D$ ratios of $0.25,0.5,1.0,2.0,4.0$, and 6.0 are investigated. Figure 22 compares the simulated overpressure attenuation from cylindrical charges with its axis vertical in Figure 15,

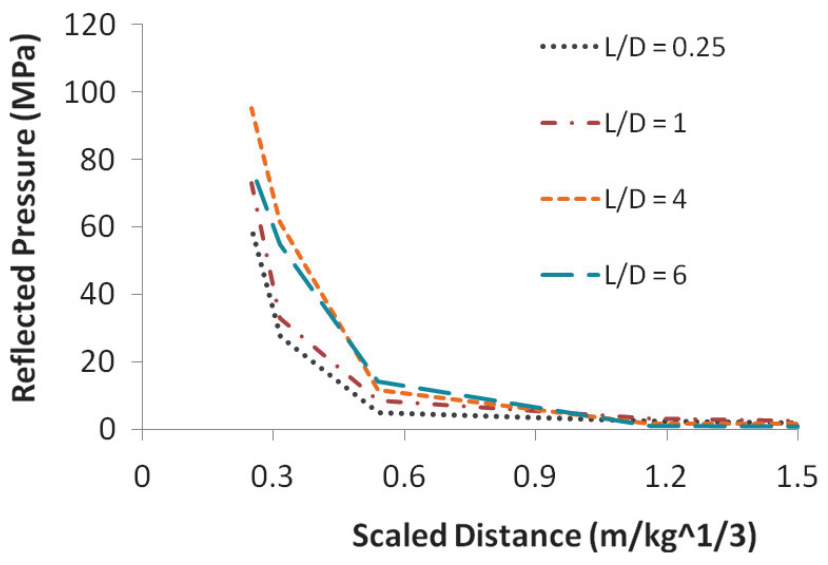

(a) Horizontal direction (radial) 


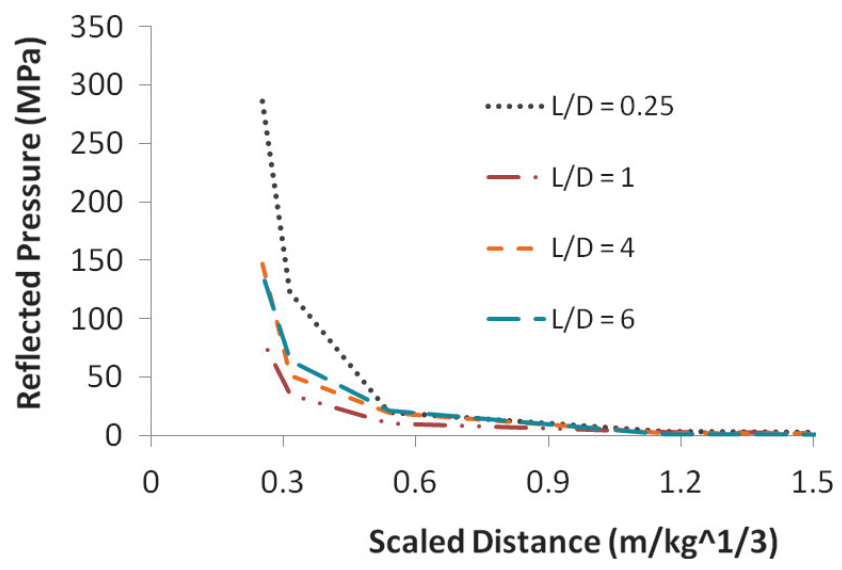

(b) Vertical direction (axial)

Figure 22. Peak reflected overpressure as a function of $L / D$ in $0.125 \mathrm{~m}^{3}$ cube

for variation of $L / D$ ratios from 0.25 to 6 in both the vertical (axial) and horizontal (radial) directions at different scaled distances. As shown the peak reflected overpressure in the horizontal direction increases significantly with an increase in $L / D$ ratios until $L / D=4.0$, but any further increase of $L / D$ ratios will reduce the peak reflected overpressure. The trends in the vertical direction are complicated but it is clear that the smaller values of the ratio will increase the peak reflected overpressure greatly. Thus the above observations show that a great portion of energy is directed axially for the charge with $L / D=0.25$, while more energy is directed radially for $L / D=$ 4.0 as highlighted for external blast loading by Zimmerman et al. (1999) and Wu et al. (2010). Figure 23 shows the overpressure attenuations of cylindrical charges with different $L / D$ ratios in a

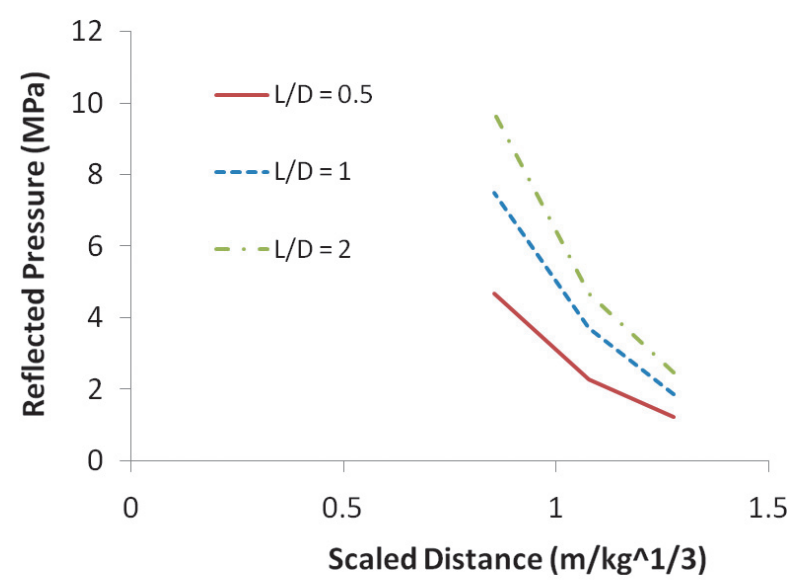

(a) Horizontal direction (radial) 


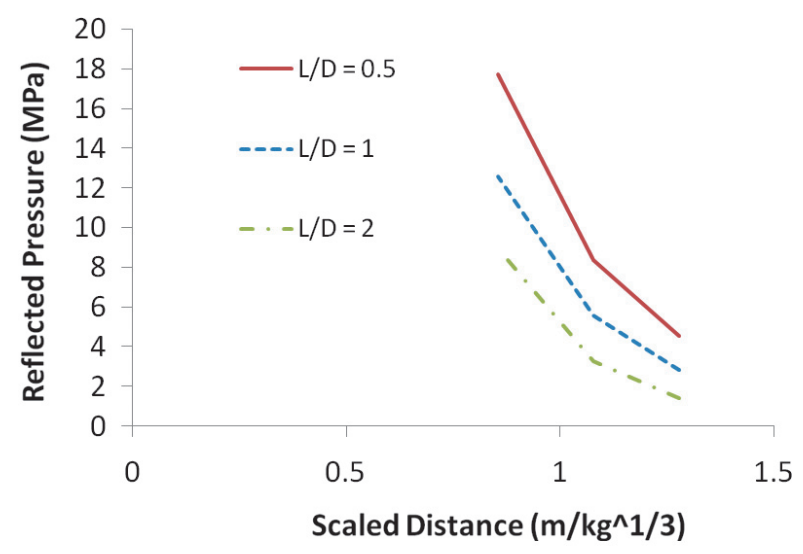

(b) Vertical direction (axial)

Figure 23. Peak reflected overpressure as a function of $L / D$ in $1 \mathrm{~m}^{3}$ cube

$1 \mathrm{~m} \times 1 \mathrm{~m} \times 1 \mathrm{~m}$ cubic box, and which provides similar trends in comparison with the ones in 0.5 $\mathrm{m} \times 0.5 \mathrm{~m} \times 0.5 \mathrm{~m}$ cube.

The peak reflected overpressure attenuation at different scaled distances grouped by aspect ratio and direction ( $\mathrm{R}=$ radial; $\mathrm{V}=$ vertical) is shown in Figure 24. From the Figure 24 it clearly demonstrates that the reflected overpressure for values of $L / D$ less than 1 in the vertical (axial) direction is substantially higher than that in the radial (Horizontal) direction, indicating that much of the energy of the detonation is directed in the vertical (axial) direction, whereas for larger values of the ratio, the reflected overpressures in axial and radial directions are similar.

\subsection{VOLUME OF CHAMBER}

Varying volumes of cubic chambers while keeping the same loading density $\left(\mathrm{kg} / \mathrm{m}^{3}\right)$ are usually considered having little influence on the overpressure data but its impact has not been quantified. In this study, its effect on overpressure is also investigated. This is done by simulating reflected overpressures for the cubic chamber of different volumes but with the same loading density. A total of three chambers of different dimensions are considered, namely, $0.25 \mathrm{~m} \times 0.25 \mathrm{~m} \times 0.25 \mathrm{~m}\left(0.015625 \mathrm{~m}^{3}\right), 0.5 \mathrm{~m} \times 0.5 \mathrm{~m} \times 0.5 \mathrm{~m}(0.125$ $\left.\mathrm{m}^{3}\right), 1 \mathrm{~m} \times 1 \mathrm{~m} \times 1 \mathrm{~m}$, corresponding to TNT load density of $0.008 \mathrm{~kg} / \mathrm{m}^{3}, 0.025 \mathrm{~kg} / \mathrm{m}^{3}$, $0.1 \mathrm{~kg} / \mathrm{m}^{3}$, and $0.5 \mathrm{~kg} / \mathrm{m}^{3}$, respectively. Figure 25 compares the overpressure histories for three cubic chamber volumes at the same scaled distance at PT1. As shown, the larger the volumes, the higher the peak overpressure, although their scaled distances are the same. The peak overpressure attenuation at different scaled distances for different volumes at centre of the wall is shown in Figure 26 and their corresponding UFC predictions are also plotted in the Figure 26 for a comparison. The impact of volumes on peak reflected overpressure is significant based on the simulated results. For external blast loading, the overpressure at the same scaled distance should be the same. However, for internal blast loading in cubic chambers, the simulated overpressure at the same scaled distance varies significantly although UFC predictions give the same value at the same scaled distance. At the same scaled distance, the larger is the volume, the higher the simulated overpressures centre of the wall. The difference between UFC predictions 


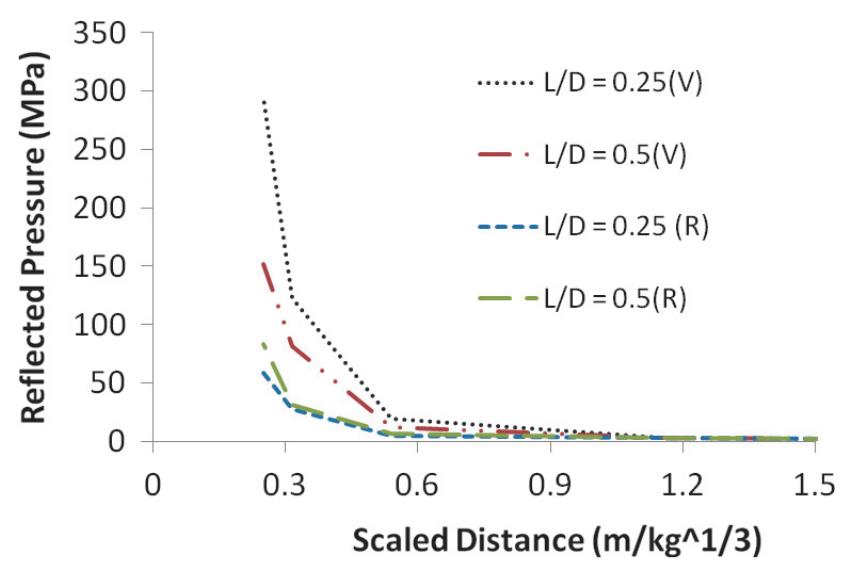

(a) L/D of 0.25 and 0.5

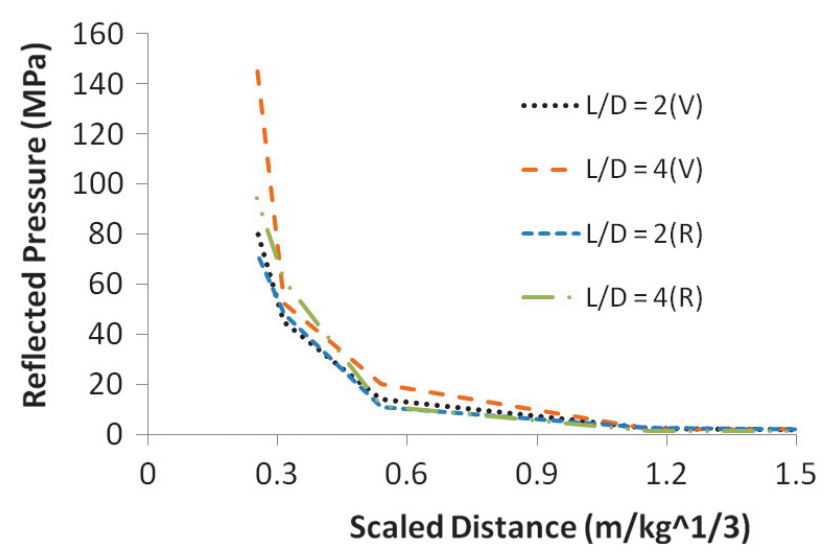

(b) L/D of 2 and 4

Figure 24. A comparison of peak reflected overpressure in radial (R) and vertical $(V)$ directions

and the simulated overpressure might be because the UFC predictions give average value of overpressure on the wall while the simulated overpressure is only at centre of the wall.

\subsection{GEOMETRY OF CHAMBER}

Effects of chamber geometry on overpressure are also investigated. The charge weight of $1 \mathrm{~g}$, $10 \mathrm{~g}, 100 \mathrm{~g}, 500 \mathrm{~g}$ and $1 \mathrm{~kg}$ and the chamber volume of $0.125 \mathrm{~m}^{3}$ are still used in the numerical simulation. Three cases are simulated, that is, cuboid with dimension in the $Z-, Y$-, and $X$-directions being $0.25 \mathrm{~m}, 1 \mathrm{~m}$, and $0.5 \mathrm{~m}$, cylinder (radius $0.271 \mathrm{~m}$, length $0.542 \mathrm{~m}$ along the $X$ direction), and the previously discussed cubic case (that is $0.5 \mathrm{~m} \times 0.5 \mathrm{~m} \times 0.5 \mathrm{~m}$ ). The spherical shape explosives are placed at the centre of the chambers as shown in Figure 27. As observed in Figure 28, cylindrical chamber has the highest reflected overpressure in 


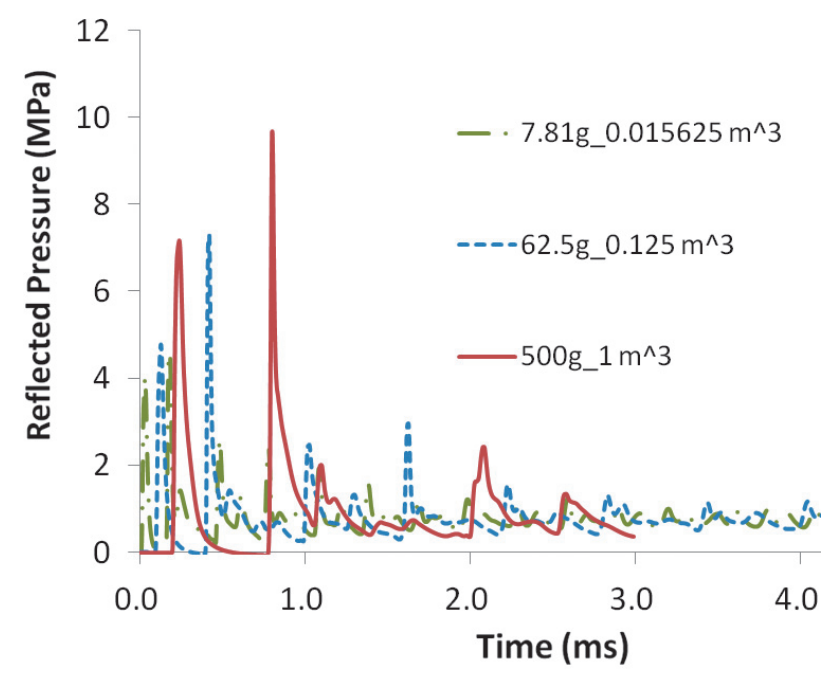

Figure 25. A comparison of overpressure histories for different cubic chamber volumes at the same scaled distance

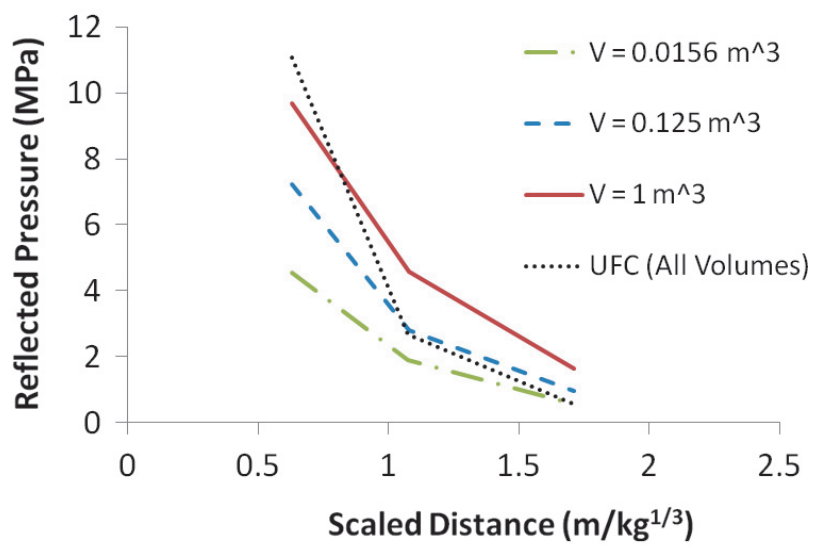

(a) overpressure

Figure 26. Peak reflected overpressure as a function of chamber volume
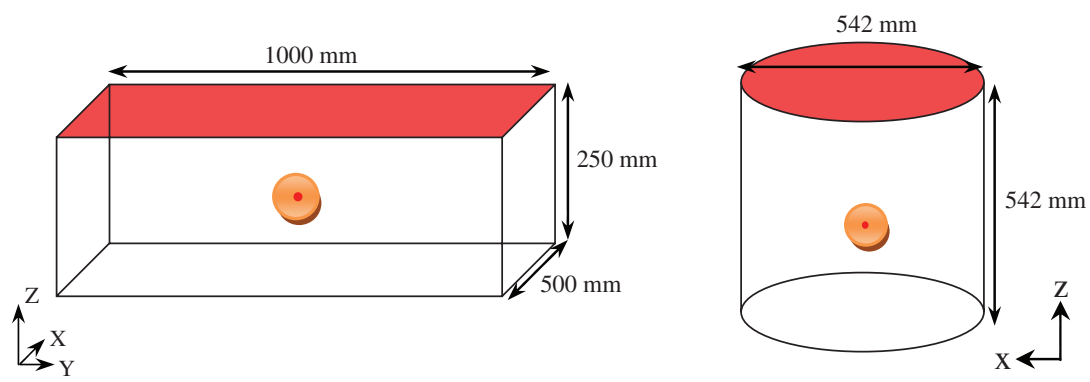

Figure 27. Chamber with explosive and detonation point in parametric studies 


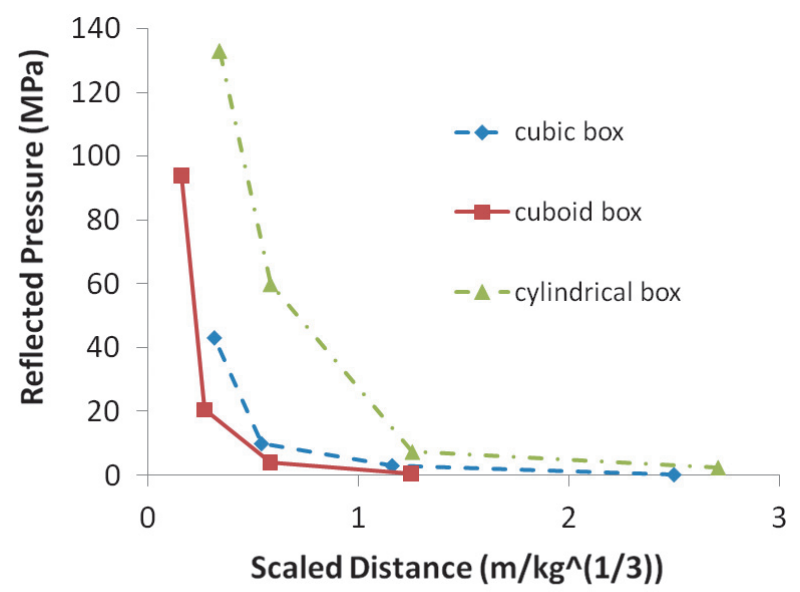

$z$ axis (vertical direction)

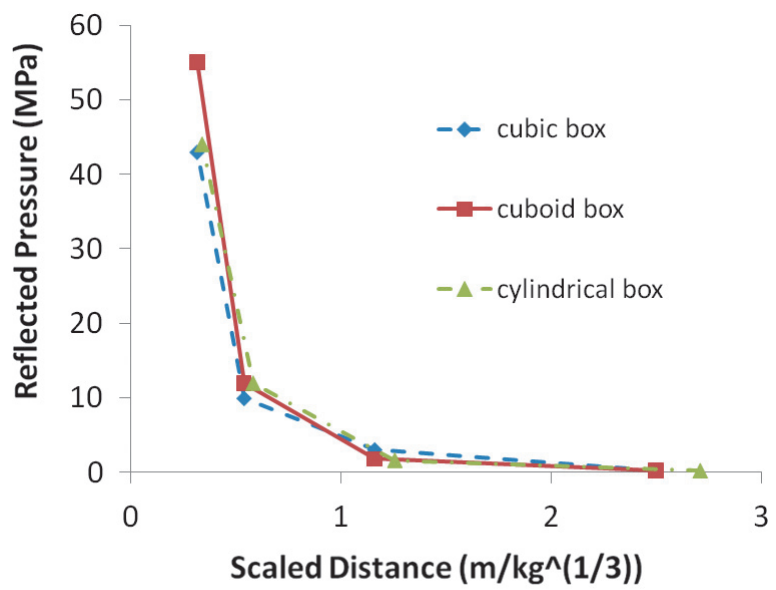

$\mathrm{x}$ axis (horizontal direction)

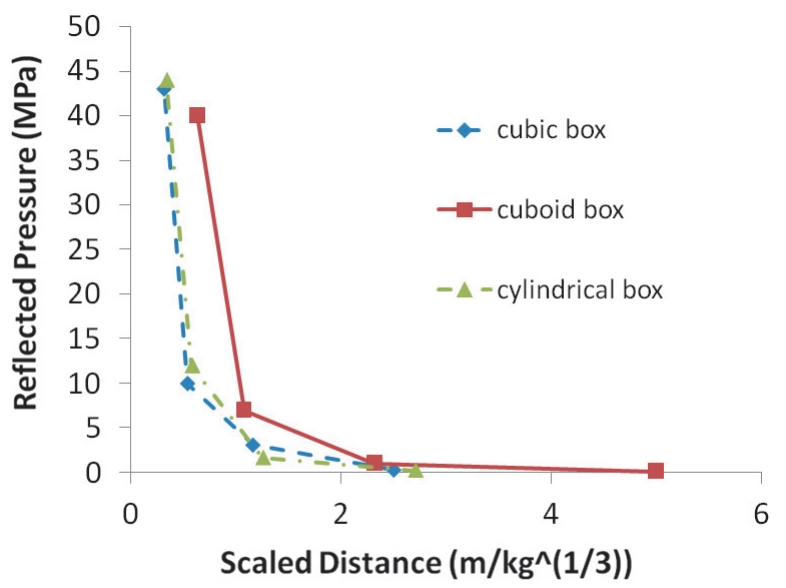

y axis (horizontal direction)

Figure 28. A comparison of peak reflected overpressure attenuation with different types of chambers in different directions 
$\mathrm{z}$ direction at the same scaled distance while the reflected overpressure in y direction of cuboid is much higher than both cubic and cylindrical chambers due to the confined effects. It is interesting to see that the reflected overpressures in $\mathrm{x}$ direction are almost the same for three different types of chambers. However, confined blast loading in cylindrical chamber is not characterized by UFC although it has the highest reflected overpressure in $\mathrm{z}$ direction. Thus the effects of chamber geometry on overpressure should be taken into consideration for confined blast loading.

\section{CONCLUSIONS}

A numerical model based on AUTODYN has been validated with available external blast testing data and confined experimental data in a small box. The validated numerical model is then used to conduct parametric studies on investigation of the variation in reflected overpressure with location on the small box by changing the orientation of the charge, the charge weight, the charge shape. It was found that there are more than five times variation of peak reflected overpressure on the walls of the small box and multiple shock reflections are observed in contradiction with UFC-3-340-02's assumption of uniformly distributed overpressure and one peak shock reflection. The validated numerical model is then used to characterize fully confined blast loading with spherical charges in cubic chamber. Based on the simulated data, the shock wave duration and quasi-static overpressure for fully confined blast loading with spherical charges are characterized and the relationships of the quasi-static overpressure and shock wave durations as a function the loading density are derived. The validated numerical model is further used to simulate the influence of charge shape, charge orientation, length to diameter $(L / D)$ ratios of cylindrical charge and volume and geometry of the chamber on reflected overpressure distribution inside chambers. It demonstrated that variation of $\mathrm{L} / \mathrm{D}$ ratios in a cubic chamber has great effects on reflected overpressure and the impact of cubic chamber volumes on peak reflected overpressure is also significant. The effects of chamber geometries on reflected overpressure should be taken into consideration for confined blast loading.

\section{ACKNOWLEDGMENTS}

This study was sponsored by an Australian Research Council linkage project LP0883451 supported by DSTO and VSL.

\section{REFERENCES}

1. American Society of Civil Engineers (ASCE). (forthcoming). Blast Protection of Buildings. Standard in preparation, Reston, VA.

2. $\quad$ Baker, W.E., Cox, P.A., Westine, P.S., Kulesz, J.J., \& Strehlow, R.A. (1983), Fundamental Studies in Engineering, Explosion Hazards and Evaluation, vol.5, pp. 238-243, Amsterdam, Oxford, New York: Elsevier.

3. Century Dynamics. (2003). AUTODYN User Manual. Revision 3.0. Century Dynamics, Inc.

4. Chan, P.C., \& Klein, H. H. (1994). A Study of blast effects inside an enclosure. Journal of Fluids Engineering-Transactions of the ASME, vol. 116, no. 3, pp. 450-455.

5. Liu, J.B., Yan, Q.S., \& Wu, J. (2008). Analysis of blast wave propagation inside tunnel. Transactions of Tianjin University, vol. 14, no. 5, pp. 358-362.

6. Remennikov, A. M., \& Rose, T.A. Modeling blast loads on buildings in complex city geometries. Computers and Structures, vol. 83, no. 27, pp. 2197-2205, 2005.

7. Savir, Z., Edri, I., Feldgun, V., Karinski, Y., \& Yankelevsky, D. (2009) Blast Pressure Distribution on Interior Walls Due to a Partially Confined Explosion. The International Workshop on Structures Response to Impact and Blast Conference, Israel, 15-17 November, CD proceeding. 
8. Shi, Y., Li, Z., \& Hao, H. (2009). Numerical Investigation of Blast Loads on RC Slabs from Internal Explosion. The International Workshop on Structures Response to Impact and Blast Conference, Israel, 15-17 November, CD proceeding

9. Smith, P.D., \& Rose, T.A. (2006). Blast wave propagation in city streets-an overview. Progress in Structural Engineering and Materials, vol. 8, no. 1, pp. 16-28.

10. Tham, C.Y. (2009). Numerical simulation on the interaction of blast waves with a series of aluminium cylinders at near-field. International Journal of Impact Engineering, no.36, pp. 122-131.

11. UFC-3-340-02. (2008). Structures to Resist the Effect of Accidental Explosions. US Department of the Army, Navy and Air Force Technical Manual.

12. Wu, C., Fattori, G., Whittaker, A., Oehlers, D.J. (2010). Investigation of air-blast effects from spherical- and cylindrical-shaped charges. International Journal of Protective Structures.vol. 1, no. 3, pp. 345-362.

13. Zhou, X.Q., \& Hao, H. (2007). Prediction of Airblast Loads on Structures Behind a Protective Barrier. International Journal of Impact Engineering, vol. 35, no. 5, pp. 363-375.

14. Zyskowski, A., Sochet, I., Mavrot, G., Bailly, P., \& Renard, J. (2004). Study of the explosion process in a small scale experiment-structural loading. Journal of Loss Prevention in the Process Industries, Vol. 17, no. 4, pp. 291-299. 